\title{
ASSESSMENT OF MARINE WATER QUALITY INDEX IN MANGROVE ESTUARINE: CASE STUDY IN SETIU RIVER ESTUARY
}

\author{
Mohd Saiful Samsudin, Azman Azid*
}

Faculty of Informatics \& Computing, Universiti Sultan Zainal Abidin (UniSZA), Besut Campus, 22200 Besut, Terengganu, Malaysia. Faculty Bioresources and Food Industry, Universiti Sultan Zainal Abidin (UniSZA), Besut Campus, 22200 Besut, Terengganu, Malaysia *Corresponding Author Email: azmanazid@unisza.edu.my

This is an open access article distributed under the Creative Commons Attribution License, which permits unrestricted use, distribution, and reproduction in any medium, provided the original work is properly cited.

\section{ARTICLE DETAILS \\ ABSTRACT}

\section{Article History:}

Received 23 December 2018

Accepted 26 January 2019

Available online 4 February 2019

This study provides information on marine water quality index in the Setiu River estuary. Mangrove estuarine and river mouth water are classified in Class E in MWQI. The subsequent MWQI with scales among 0 to 100 will define the grouping of the marine water quality from "Excellent" to "Poor". Six sampling station has been choosing and the sampling activity has been done from July 2016 to January 2017. Post-hoc Tukey HSD test calculates by evaluating whether MWQI for ST1 is more than the critical MWQI value for all relevant pairs of treatments. The test is also performed by using studentized range distribution as well as p-values corresponding to an observed value of MWQI. Continuous monitoring of water quality in mangrove estuarine and river so that it is possible to preserve the quality of mangrove estuarine ecosystem.

\section{KEYWORDS}

water quality, marine water quality index, mangrove estuarine zone, analysis of variance, post hoc Tukey HSD.

\section{INTRODUCTION}

The study on marine water quality uses a very broad method in either at the island, the coast, the middle of the sea or the estuary area. In Malaysia, research involving marine water quality in mangroves ecosystem is not well-recorded and only a little information is known concerning the marine water quality of the mangroves distribution compared to the requirements of the Department of Environment, Malaysia (DOE). Generally, the mangrove systems (river, estuary and wetland) obtain numerous pollutants and have become an immense pollution sink in recent decades [1]. The water quality index (WQI) has been contemplated to give criteria for surface water classification based on the use of standard parameters for water characterization [2]. WQI development is the biggest challenge in order to synthesize a complex reality in a single number since it is directly affected by many environmental variables [3]. Hence, a clear definition of the goals to be attained using such index is obligatory. This index is a mathematical instrument used to transform large quantities of water characterization data into a single number, which represents the water quality level.

The employment of WQI is a simple practice, which allows acceptable classification of water quality. According to a researcher, WQI was used as a basis for assessment of watercourse in relation to pollution load categorization and designation of classes of beneficial uses as stipulated in the National Quality Standard of Malaysia (NWQS). According to Malaysia Environmental Quality Report 2016, marine water quality data have been collected for analyses and reported based on the Marine Water Quality Index (MWQI). The MWQI is used as a method to reflect the marine water quality status and have seven main parameters (Dissolved Solid (DO), Nitrate (NO3), Phosphate (PO4), Unionized Ammonia (NH3), faecal coliform, oil and Grease (O\&G), and Total Suspended Solid (TSS). Mangrove estuarine and river mouth water are classified in Class E in MWQI. In Table 1 , the subsequent MWQI with scales among 0 to 100 will define the grouping of the marine water quality from "Excellent" to "Poor" [4].
Table 1: Marine Water Quality Index Classification

\begin{tabular}{ll}
\hline Category & Index Value \\
\hline Excellent & $90-100$ \\
Good & $80-<90$ \\
Moderate & $50-<80$ \\
Poor & $0-<50$ \\
\hline
\end{tabular}

There are three groups of quality elements (biological, hydromorphological and physicochemical) that have been recognized to categorize the ecological status of a water body in the water framework directive $[5,6]$. This referred to certify that the estuary water is protected for the habitat, aquatic and wildlife species and for mankind [7,8]. In recent time, many issues have been raised among the public on how to achieve the most satisfactory level and pattern of marine water quality in the mangrove estuary area. This study provides information on marine water quality index in Setiu River estuary.

\section{METHODOLOGY}

\subsection{Study area}

The sampling points were recognised before the sampling activities in order to access and exactly so signify the existing pollution sources based on seven MWQ parameters from DOE criteria (Class E). Six sampling point has been choosing in Setiu River estuary and situated at Setiu district, Terengganu and originated from Setiu River Basin (Figure 1). This estuary has catchment area $188 \mathrm{~km}^{2}$ approximately and is $52 \mathrm{~km}$ long and 148535 $660.9 \mathrm{~m}^{2}$ immensities. Setiu River estuary covers 23000 ha area and the water column is well mixed and shallow [9]. 


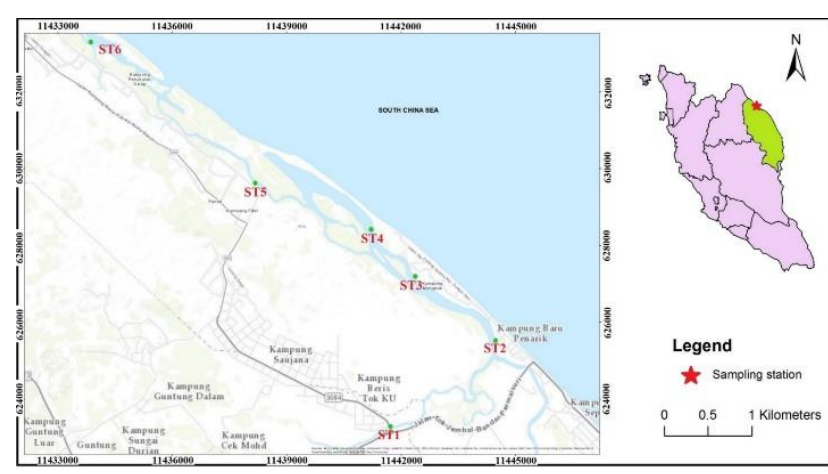

Figure 1: Location of sampling stations in Setiu River estuary

\subsection{Surface marine water sampling and analytical procedure}

The MWQ parameters selected in this study refers to the Marine Water Quality Index (MWQI) (DOE, 2017) as a guideline which includes DO, NH3, TSS, NO3, O\&G, P04 and faecal coliform. Triplicates and homogenized surface water samples were collected from six sampling stations from July 2016 to January 2017. The water samples were collected during normal tide from all sampling stations. The collected surface water samples $30 \mathrm{~cm}$ depth from the top using water sampler vertically. All the samples were kept in acid-washed $1 \mathrm{~L}$ high-density polyethene (HDPE) bottles and transported to the laboratory at $<4{ }^{\circ} \mathrm{C}$. Surface water quality was measured onsite for the in-situ parameters at each station for DO and NH3N at one meter below the water surface using parameter probe YSI Multi-Parameter Water Quality Sonde. Immediately after sampling, the samples were transferred into the cooler box with dry ice and transport back to UniSZA laboratory within 24 hours of sampling time.

The reagents and laboratory equipment used for water analysis is shown in Table 2. The reagents used were of the analytical grade in order to safeguard dependable representatives of all analytical results. Additionally, laboratory glassware and apparatuses used in this study were pre-cleaned with $5 \%$ HNO3. $1 \mathrm{ml}$ of water sample was transferred into a $10 \mathrm{ml}$ PP volumetric flask and made up to $10 \mathrm{ml}$ with $1 \%$ Suprapure grade HNO3 solution, prepared from ultrapure water from Milli-Q®. Besides, ultrapure water from Milli- $\mathrm{Q} \AA$ also used for laboratory applications

Table 2: Summary of reagent and laboratory equipment for MWQ parameter analysis

\begin{tabular}{lll}
\hline Parameter & Equipment & Reagent/Chemical \\
\hline $\mathrm{DO}, \mathrm{NH}_{3} \mathrm{~N}$ & YSI Multi Parameter Water Quality Sonde (YSI 556) & \\
\hline Faecal Coliform & $3 \mathrm{M}^{\mathrm{TM}}$ Petrifilm EC Plate; incubator & \\
\hline Oil and Grease & separatory funnel; filter paper & HCL;100 \% n-hexane; $\mathrm{Na}_{2} \mathrm{SO}_{4}$ \\
\hline $\mathrm{NO}_{3}$ & HACH meter (DR2800); HACH Reactor (DRB 200) & NitraVer5, Nitrate reagent powder pillow \\
\hline $\mathrm{PO}_{4}$ & HACH meter (DR2800); HACH Reactor (DRB 200) & PhosVer3, Phosphate reagent powder pillow, Test 'N Tube \\
\hline $\mathrm{TSS}$ & vacuum pump; membrane filter & \\
\hline
\end{tabular}

\subsection{Statistical analysis}

Based on the Malaysia Environmental Quality Report 2016 (DOE, 2017), MWQI was acquired using the following equation 1 :

MWQI $=\operatorname{SIDO}^{0.2} \mathrm{x} \mathrm{SINH}_{3} 0.16 \times \operatorname{SIFC}^{0.14} \times \operatorname{SITSS}^{0.14} \times \operatorname{SIO}^{0} G^{0.13} \mathrm{x} \mathrm{SINO}_{3}{ }^{0.12} \mathrm{x}$ $\mathrm{SIPO}_{4}^{0.11}$

The statistical significant difference between all MWQ parameters was evaluated using one-way analysis of variance (ANOVA). Regarding multiple comparisons, the variables were statistically compared using Tukey Honest significant difference (HSD) analysis at the confident level of $95 \%$.

\section{METHODOLOGY}

\subsection{One-way ANOVA with Post Hoc Tukey HSD}

The mean of MWQI for Setiu River estuary measured 72.65. Thus, this estuary classified as Moderate $(50-<80)$ in Marine Water Quality Index
Classification (DOE, 2017). For describing the changes, validating the experimental finding and having a right conclusion for MWQI, one-way ANOVA with post hoc Tukey HSD test was constructed on sampling data for each sampling point to have the statistical significance test.

The p-value corresponds to the F-statistic of one-way ANOVA is lower than 0.05 , strongly suggesting that one or more sampling stations are significantly different. In some cases of the Tukey HSD test, the p-value corresponding to the F-statistic of one-way ANOVA is lower than 0.05 which strongly suggests that one or more sampling stations are significantly different (Table 3 ). Here, the present study used $k=2$ sampling station, for which one shall apply Tukey's HSD test to each of the 1 sampling stations to pinpoint which of them exhibits statistically significant difference.

Firstly, the critical value of the Tukey HSD was established for significance level 0.05 (p-values) in the Studentized Range distribution. The results obtain these critical values for sampling stations at Setiu River estuary, for as 4.1077 (Table 4).

Table 3: Analysis of Variance for MWQI in Setiu River estuary's sampling station

\begin{tabular}{llllll}
\hline Source & DF & Sum of squares & Mean squares & F & Pr $>$ F \\
\hline Model & 5 & 8740.788 & 1748.158 & 13.325 & $<\mathbf{0 . 0 0 0 1}$ \\
Error & 102 & 13381.488 & 131.191 & & \\
Corrected Total & 107 & 22122.276 & & & \\
\hline
\end{tabular}

Table 4: Station / Tukey (HSD) / Analysis of the differences between the categories with a confidence interval of 95\% (MWQI) in Setiu River estuary

\begin{tabular}{llllll}
\hline Contrast & Difference & Standardized difference & Critical value & Pr $>$ Diff & Significant \\
\hline ST1 vs ST4 & 25.294 & 6.625 & 2.905 & $<\mathbf{0 . 0 0 0 1}$ & Yes \\
ST1 vs ST6 & 23.078 & 6.045 & 2.905 & $<\mathbf{0 . 0 0 1}$ & Yes \\
ST1 vs ST5 & 17.417 & 4.562 & 2.905 & $\mathbf{0 . 0 0 0}$ & Yes \\
ST1 vs ST2 & 16.878 & 4.421 & 2.905 & $\mathbf{0 . 0 0 0}$ & Yes \\
ST1 vs ST3 & 6.039 & 1.582 & 2.905 & 0.612 & No \\
ST3 vs ST4 & 19.254 & 5.043 & 2.905 & $<\mathbf{0 . 0 0 0 1}$ & Yes \\
ST3 vs ST6 & 17.039 & 4.463 & 2.905 & $\mathbf{0 . 0 0 0}$ & Yes \\
ST3 vs ST5 & 11.378 & 2.980 & 2.905 & $\mathbf{0 . 0 4 1}$ & Yes \\
ST3 vs ST2 & 10.839 & 2.839 & 2.905 & 0.059 & No
\end{tabular}




\begin{tabular}{llllll} 
ST2 vs ST4 & 8.416 & 2.204 & 2.905 & 0.245 & No \\
ST2 vs ST6 & 6.200 & 1.624 & 2.905 & 0.585 & No \\
ST2 vs ST5 & 0.539 & 0.141 & 2.905 & 1.000 & No \\
ST5 vs ST4 & 7.877 & 2.063 & 2.905 & 0.315 & No \\
ST5 vs ST6 & 5.661 & 1.483 & 2.905 & 0.676 & No \\
ST6 vs ST4 & 2.215 & 0.580 & 2.905 & 0.992 & No \\
\hline
\end{tabular}

\subsection{The summary from one-way ANOVA with post hoc Tukey HSD}

Post-hoc Tukey HSD test calculates by evaluating whether MWQI for ST1 is more than the critical MWQI value for all relevant sampling stations. The test is also performed by using studentized range distribution as well as pvalues corresponding to an observed value of MWQI. The statistics in Table 5 concludes that even though the MWQI for ST1 is somewhat better accuracy than others, still it is not that much significant to outweighs the other.

Table 5: Station / Tukey (HSD) / Analysis of the differences between the categories with a confidence interval of $95 \%$ (MWQI)

\begin{tabular}{lllll}
\hline Category & LS means (MWQI) & \multicolumn{2}{l}{ Groups } & \\
& & & & \\
\hline ST1 & 87.437 & A & & \\
ST3 & 81.398 & A & B & \\
ST2 & 70.559 & & B & C \\
ST5 & 70.02 & & & C \\
ST6 & 64.359 & & & C \\
ST4 & 62.144 & & C \\
\hline
\end{tabular}

Consequently, the present study found the following MWQI for sampling stations in Setiu river estuary have slightly different value because of the variability of MWQ concentrations. It is well understood that MWQI for Setiu River estuary results in low accuracy in comparison to sampling stations. To get a better understanding of post hoc tests, Table 5 indicates the summary of all pairwise comparison for all sampling stations. In combinations that include MWQI, ST1 and ST3 share the same letter (A) and have no letter in common with ST2, ST5 and ST6 which also share the same letter (C). This means that the two groups of stations not significant on MWQI.

Figure 2 signify Least Significant (LS) means for all station. The chart shows that, notwithstanding of the MWQI, stations mostly not significant, which is supported by p-values associated with the station's effects in the ANOVA model.

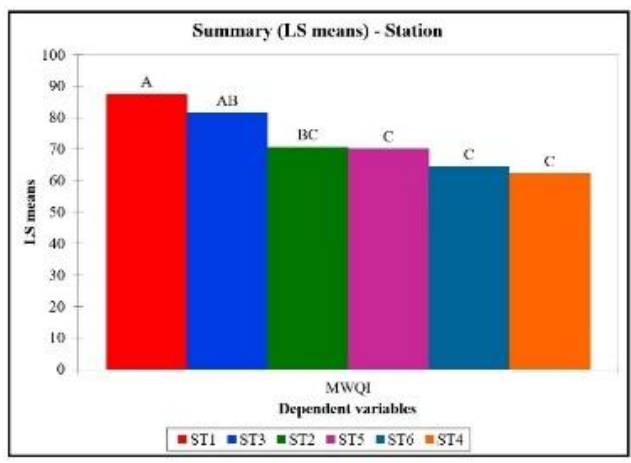

Figure 2: LS means chart for Setiu River estuary

\section{CONCLUSION}

This study will be improving the valuation of the protective service of mangroves estuarine water, along with the other advantages delivered by this crucial ecosystem, may prove important in these future mangrove estuarine management decisions. Continuous monitoring of water quality in mangrove estuarine and river so that it is possible to preserve the quality of mangrove estuarine ecosystem. Thus, a vulnerable area such mangrove estuarine ecosystem should receive specific attention to prevent the water quality from further deterioration and control the pollution load from the point and non-point sources.

\section{REFERENCES}

[1] Samsudin, M.S., Khalit, S.I., Azid, A., Yunus, K., Zaudi, M.A., Badaluddin, N.A., Saudi, A.S.M. 2017. Spatial analysis of heavy metals in mangrove estuary at east coast peninsular Malaysia: a preliminary study. Journal of Fundamental and Applied Sciences, 9(2S), 680-697.

[2] Hernández-Romero, A.H., Tovilla-Hernández, C., Malo, E.A., BelloMendoza, R. 2004. Water quality and presence of pesticides in a tropical coastal wetland in southern Mexico. Marine Pollution Bulletin, 48(11-12), 1130-1141.

[3] Lermontov, A., Yokoyama, L., Lermontov, M., Machado, M.A.S. 2009. River quality analysis using fuzzy water quality index: Ribeira do Iguape river watershed, Brazil. Ecological Indicators, 9(6), 1188-1197.

[4] Al-Mamun, A., Zainuddin, Z. 2013. Sustainable river water quality management in Malaysia. IIUM Engineering Journal, 14(1).

[5] Department of Environment, M. (DOE). 2017. Malaysia Environmental Quality Report 2016. Putrajaya, Malaysia, 1-135

[6] Buck, O., Niyogi, D.K., Townsend, C.R. 2003. Scale-dependence of land use effects on water quality of streams in agricultural catchments. Environmental Pollution 130 (10.1016/j.envpol), 287-299.

[7] Allen, P.D., Richard, H.M. 2005. Storm water Management for Smart Growth. United States of America, Springer Science + Business Media, Inc. [8] Bouza-Deano, R., Ternero-Rodriguez, M., Fernandez-Espinosa, A.J. 2008. Trend study and assessment of surface water quality in the Ebro River (Spain). Journal of Hydrology 361, 227-239.

[9] Suratman, S., Hussein, A.N.A.R., Latif, M.T., Weston, K. 2014. Reassessment of physico-chemical water quality in Setiu Wetland, Malaysia. Sains Malaysiana, 43(8), 1127-1131 